\title{
PEMANFAATAN LIMBAH STRAPPING BAND dan STYROFOAM dengan MENGGUNAKAN PASIR MOJOKERTO untuk BATA RINGAN
}

\author{
Safrin Zuraidah ${ }^{1)}$, Bambang Sujatmiko', \\ Jeremias Gualdin $\mathbf{F}^{3}$, \\ 1) Prodi Teknik Sipil, Fakultas Teknik, Universitas Dr. Soetomo, safrin.zuraidah@unitomo.ac.id \\ 2) Prodi Teknik Sipil, Fakultas Teknik, Universitas Dr. Soetomo \\ ${ }^{3)}$ Prodi Teknik Sipil, Fakultas Teknik, Universitas Dr. Soetomo
}

\begin{abstract}
ABSTRAK
Limbah strapping band dan styrofoam dari bekas kemasan untuk makanan dan pengikat kemasan elektronik saat ini banyak digunakan di pusat pembelanjaan, hal ini akan berdampak terhadap pencemaran lingkungan , karena limbah strapping band dan styrofoam yang berbahan dasar plastik dan sulit diurai oleh tanah. Dalam rangka mengurangi limbah yang berbahan plastic untuk menjaga pelestarian lingkungan dengan upaya memanfaatkan limbah tersebut sebagai bahan penyusun dalam campuran bata ringan. Penelitian ini bertujuan untuk pemamfaatan limbah fiber strapping band dan styrofoam untuk campuran penyusun bata ringan dengan menguji terhadap Kuattekan dan berat volume bata ringan. Dalam penelitian ini penambahan fiber Strapping Band dengan panjang $40 \mathrm{~mm}$ dan $50 \mathrm{~mm}$ dan komposisi $0 \%, 3 \%, 6 \%, 9 \%$ terhadap berat semen, styrofoam $20 \%$ dan foam agent $0,6 \mathrm{l} / \mathrm{m} 3$. Metode yang digunakan adalah metode eksperimental yang dilaksanakan di Laboratorium material beton. Benda uji Berbentuk silinder dengan diameter $15 \mathrm{~cm}$ dan tinggi $30 \mathrm{~cm}$ dengan jumlah benda uji 72 untuk pengujian kuat tekan, kuat tarikbelah dan Berat Volume pada umur 21 dan 28 hari. Dari hasil penelitian ,terjadi peningkatan terhadap kuat tekan dan kuat tarik belah, sedangkan berat volume mengalami penurunan yang signifikan setelah penambahan serat fiber strapping band, Kuat tekan maksimum terjadi pada komposisi serat fiber strapping band 9\% sebesar 7,445 Mpa (meningkat 139,4\%) dan kuat tarik belah sebesar 0,94 Mpa (meningkat 54,1\%), sedangkan berat volume hasilnya $1421 \mathrm{~kg} / \mathrm{m} 3$ (lebihringan2,34\%), bila dibandingkan dengan bata ringan tanpa serat. Berat volume standart beton ringan antara $600-1600 \mathrm{~kg} / \mathrm{m} 3$
\end{abstract}

Kata Kunci : Bata ringan, Fiber, Kuat Tekan, Kuat Tarik, Berat Volume

\section{PENDAHULUAN}

Pertumbuhan sektor ekonomi negara Indonesia mengalami kemajuan yang cukup pesat. Hal ini didukung dengan begitu banyaknya industri seperti industri elektronik yang tersebar di Indonesia. Industri tersebut dalam menjalankan usahanya tidak pernah lepas dari bagian pengemasan sebelum proses distribusinya, seperti pengemasan alat elektronik yang menggunakan tali fiber strapping band dan menggunakan styrofoam. Pengemasan dalam industri bertujuan untuk mengamankan proses distribusi agar produk tetap aman sampai pada tangan konsumen.Disamping begitu banyaknya penggunaan tali fiber strapping band dan styrofoam dalam pengemasan produk industri, berdampak langsung pada pencemaran lingkungan dikarenakan limbah strapping band dan styrofoam yang berbahan dasar plastik diketahui sulit untuk diurai tanah.Hal ini tentunya menjadi perhatian dalam menjaga lingkungan, dengan berupaya menjadikan limbah tersebut agar bisa dimanfaatkan kembali tanpa harus merusak lingkungan dengan memanfaatkan limbah tersebut sebagai bahan penyusun campuran bata ringan. unutuk mengurangi dampak negatif terhadap lingkungan. 


\section{NAROTAMA JURNAL TEKNIK SIPIL e-ISSN: 2460-3430 VOLUME 3 NOMOR 1 JUNI 2019}

Dengan banyaknya penelitian yang dilakukan untuk meningkatkanperfomancebata ringan, maka dalam penelitian ini menggunakan polyprophylene dari strapping band sebagai salah satu material penyusun beton untuk mendapat sifat - sifat mekanik beton yang lebih baik yang meliputi kuat tekan,kuat tarik belah dan berat volume.

\section{TINJAUAN PUSTAKA}

Bata ringan adalah batu bata yang memiliki berat jenis yang lebih ringan dari pada bata konvensional. Bata ringan dikenal ada 2 (dua) jenis: Autoclaved Aeratedv concrete (AAC) dan cellular lightweight concrete (CLC). Keduanya di dasarkan pada gagasan yang sama yaitu menambahkan gelembung udara ke dalam mortar akan mengurangi berat beton yang dihasilkan secara dratis. Perbedaan bata ringan Autoclaved Aeratedv concrete (AAC) dan cellular lightweight concrete (CLC) dari segi proses pengeringan yaitu bata ringan Autoclaved Aeratedv concrete (AAC) mengalami pengeringan dalam oven autoklaf bertekan tinggi, sedangkan bata ringan cellular lightweight concrete (CLC) yang mengalami proses pengeringan alami. Bata ringan pertama kali dikembangkan di Swedia pada tahun 1923 sebagai alternatif material bangunan. Pada tahun 1943 bata ringan dikembangkan lagi oleh Joseph Hebel di Jerman. Di Indonesia bata ringan dikenal pada tahun 1995 saat didirikan PT. Hebel Indonesia di Karawang Timur, jawa barat (Wijayanti, W., $2012: 55)$.

Menurut Ngabdurrochman (2009), bata ringan adalah bata berpori yang memiliki berat jenis (density) lebih ringan dari pada bata pada umumnya. Berat jenisya antara 600 - 1600 $\mathrm{kg} / \mathrm{m} 3$ dengan kekuatannya tergantung pada komposisi campuran (mix design).

Menurut A. Short \& W. Kinniburgh (1978), bata ringan adalah material yang meyerupai beton dan memiliki sifat kuat, tahan air, api dan awet (durable). Bata ini cukup ringan, halus dan memiliki tingkat kerataan yang baik. Bata ringan diciptakan agar dapat memperingan beban struktur dari sebuah bangunan konstruksi, mempercepat pelaksanaan.

Material Penyusun Bata Ringan

Semen Portland

Dari beberapa jenis semen, yang sering digunakan dalam konstruksi beton adalah jenis semen portland. semen portland adalah semen hidrolik dengan cara menghaluskan klinker yang terdiri dari kalsium silka yang bersifat hidrolik. Fungsi semen adalah untuk merekatkan butir-butir agregat terjadi suatu massa yang padat dan mengisi rongga-rongga antar butir agregat.

Agregat 


\section{NAROTAMA JURNAL TEKNIK SIPIL e-ISSN: $2460-3430$ VOLUME 3 NOMOR 1 JUNI 2019}

Agregat merupakan komponen yang cukup penting dalam material penyusun beton. Selain berpengaruh terhadap jenis dan kekuatan beton yang dihasilkan, agragat juga berpengaruh terhadap nilai ekonomis beton karena material ini mudah didapat dan relatif murah. Proporsi agregat dalam campuran beton kira-kira $70 \%-80 \%$ volume beton.

Air

Fungsi air pada pembuatan beton adalah membantu reaksi kimia semen portland dan sebagai bahan pelicin antara semen dengan agregat agar mudah dikerjakan.

Bahan Tambahan

Bahan tambah bertujuan untuk mengubah sifat betonnya. Bahan tambah digunakan untuk memodifikasi sifat dan karakteristik dari beton misalnya untuk dapat dengan mudah dikerjakan.

\section{PengujianBeton:}

\section{Kuat tekan Beton}

Kuat tekan beton adalah kemampuan beton keras untuk menahan gaya tekan dalam setiap satu satuan luas permukaan beton. Secara teoritis, kekuatan tekan beton dipengaruhi oleh kekuatan komponen-komponennya

\section{Kuat TarikBelah Beton}

Kuat tarik belah beton benda uji silinder beton nilai kuat tarik tidak langsung dari benda uji beton berbentuk silinder yang diperoleh dari hasil pembebanan benda uji tersebut yang diletakkan mendatar sejajar dengan permukaan meja penekan mesin uji. Kuat tarik belah seperti inilah yang diperoleh melalui metode pengujian kuat tarik belah dengan Universal Testing Machine(UTM). Salah satu kelemahan beton adalah mempunyai kuat tarik yang sangat kecil dibandingkan dengan kuat tekannya yaitu sekitar 10\% - 15\% dari kuat tekannya. Kuat tarik beton merupakan sifat yang penting untuk memprediksi retak dan defleksi.

\section{Berat Volume}

Berat volume adalah perbandingan berat beton terhadap volume beton itu sendiri.

\section{Porositas}

Porositas adalah ukuran dari ruang kosong di antara material, dan merupakan fraksi dari volume ruang kosong terhadap total volume, yang bernilai antara 0 dan1, atau sebagai persentase antara $0-100 \%$. 


\section{NAROTAMA JURNAL TEKNIK SIPIL \\ e-ISSN: 2460-3430 \\ VOLUME 3 NOMOR 1 JUNI 2019}

\section{METODE PENELITIAN}

Secara umum tahapan penelitian dijelaskan melalui diagram alir penelitian seperti gambar 1.

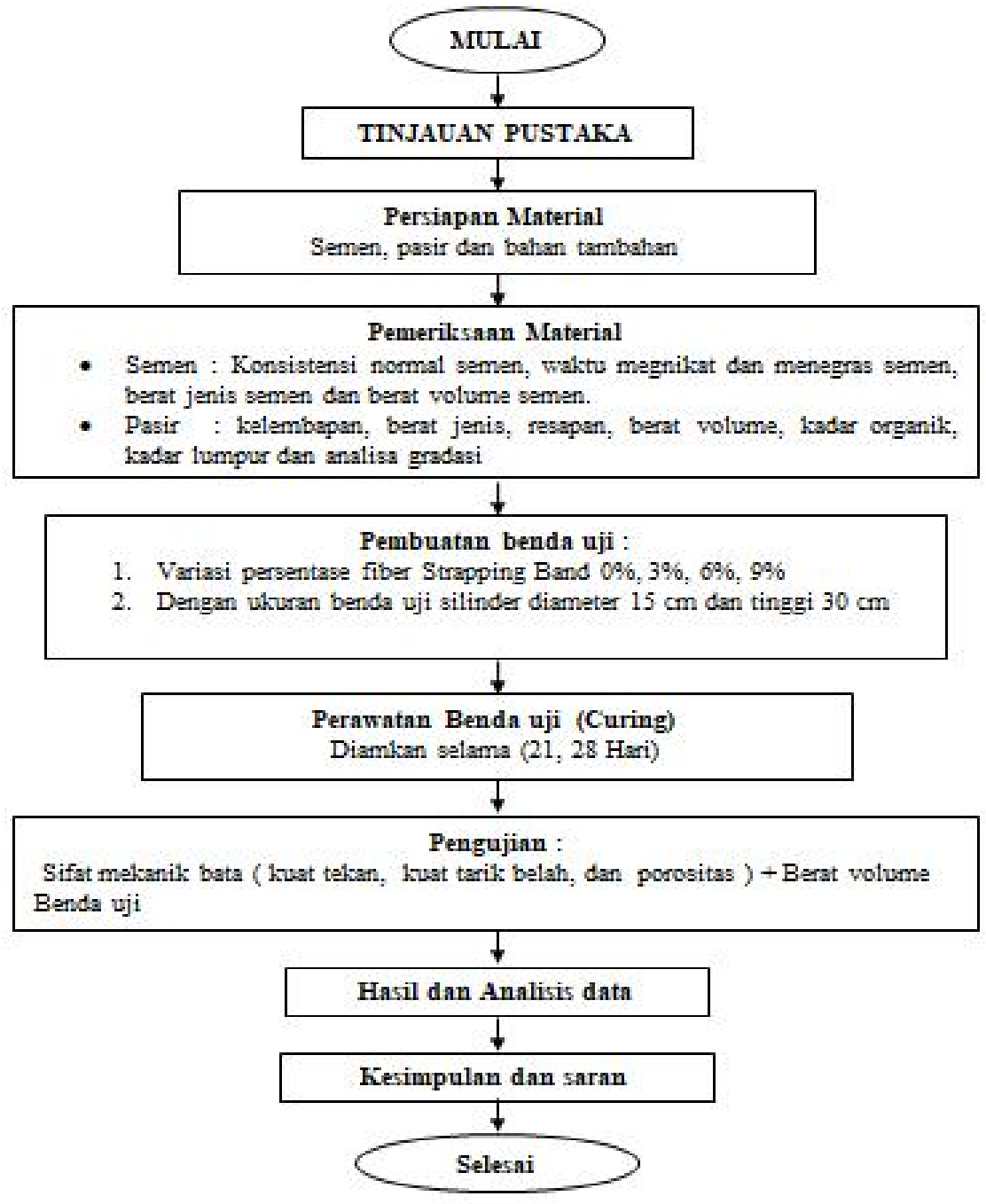

Gambar 1 Diagram Alir Penelitian 


\section{NAROTAMA JURNAL TEKNIK SIPIL e-ISSN: $2460-3430$ VOLUME 3 NOMOR 1 JUNI 2019}

\section{Pengujian Mutu Material}

\section{Pengujian Bahan semen}

Dalam pengujian bahan semen ini semen yang dipakai adalah semen portland type I yang diproduksi oleh PT. Semen Holcim Indonesia. Pengujian bahan semen meliputi Percobaan konsistensi normal semen Portland (ASTM C 187 - 86), waktu pengikatan dan pengerasan semen (ASTM C 191 - 92), berat jenis semen (ASTM C 188 - 89), dan berat volume semen (ASTM C $188-89$ ).

\section{Pengujian Material Agregat}

Dalam penelitian ini agregat yang digunakan adalah agregat yang berasal diri daerah Mojokerto. Pengujian material agregat meliputi percobaan kelembaban (ASTM C 556 89), berat jenis (ASTM C 128 - 93), air resapan pasir (ASTM C 128-93), berat volume (ASTM C 29/C 29 M - 91), kebersihan terhadap bahan organik (ASTM C 40 92),kebersihan terhadap lumpur (pengendapan), kebersihan terhadap lumpur (pencucian) (ASTM C 117 - 95), dan percobaan analisa saringan (ASTM C 136 - 95a).

\section{Peralatan Yang Digunakan}

Penelitian ini menggunakan alat-alat yang tersedia di Laboratorium Teknologi Beton Program Studi Teknik Sipil Fakultas Teknik Universitas DR. Soetomo Surabaya.

\section{Tahapan pengujian}

\section{Uji kuat tekan}

Kuat tekan beton adalah besarnya beban per satuan luas, yang menyebabkan benda uji beton hancur bila diberi beban dengan gaya tekan tertentu yang dihasilkan oleh mesin. Pengujian kuat tekan silinder beton dengan menggunakan mesin (Compression Testing Machine) di Laboratorium Teknologi Beton Program Studi Teknik Sipil Fakultas Teknik Universitas Dr.Soetomo. Untuk mendapatkan besaran kuat hancur dari benda uji tesebut dilakukan perhitungan dengan rumus :

$$
\text { Fc' }^{\prime}=\frac{P}{\boldsymbol{A}}
$$

\section{Keterangan :}

$F c^{\prime} \quad=$ Kuat Tekan Beton $(\mathrm{N} / \mathrm{mm} 2)$

$P \quad=$ Beban Maksimum $(N)$

$A \quad=$ Luas Penampang yang $\left(\mathrm{mm}^{2}\right)$

2. Uji kuat tarik belah

Pengujian kuat tarik belah beton juga menggunakan mesin uji desak (CompressionTesting Machine). Langkah-langkah pengujian sama dengan uji kuat Tekan, tetap silinder diletakkan pada alat pembebanan dengan posisi mendatar (rebah). Beban $\mathrm{P}$ 


\section{NAROTAMA JURNAL TEKNIK SIPIL \\ e-ISSN: $2460-3430$ \\ VOLUME 3 NOMOR 1 JUNI 2019}

bekerja pada kedua sisi silinder sepanjang 1 dan disebarluaskan seluas selimut silinder. Secara berangsur-angsur beban dinaikkan sehingga mencapai nilai maksimum dan silinder terbelah oleh gaya tarik horizontal. Dari beban maksimal yang dapat diterima, kekuatan tarik belah dapat dihitung dengan rumus sebagai berikut:

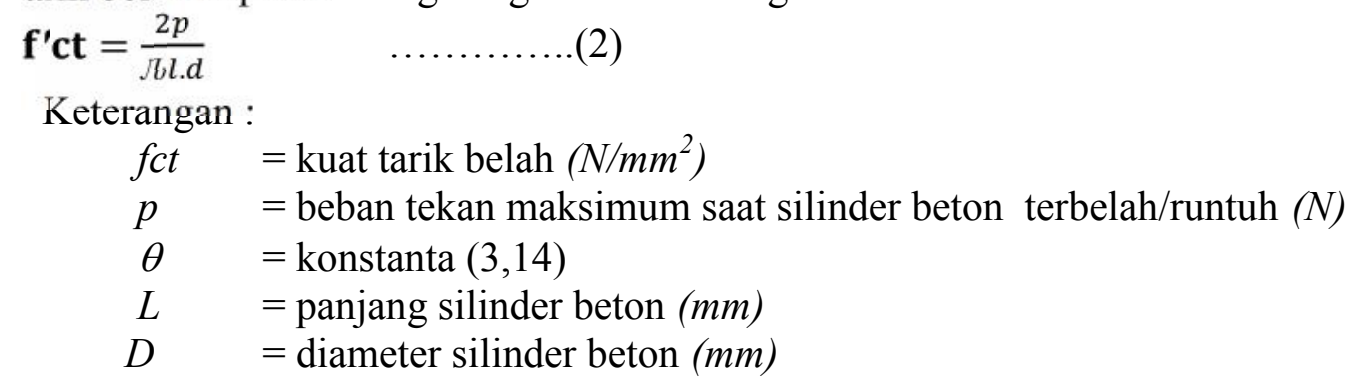

3. Uji berat volume

Berat volume adalah perbandingan berat beton terhadap volume beton itu sendiri. Satuan sistem internasional untuk berat volume adalah $\mathrm{kg} / \mathrm{m}^{3}$. Dengan menggunakan rumus

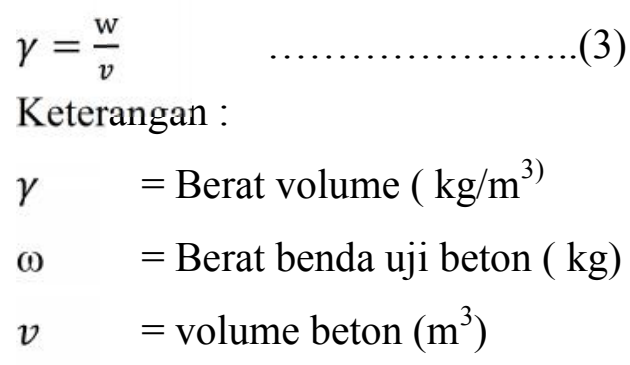

\section{Uji Porositas}

Pengujian porositas dilakukan dengan menggunakan benda uji silinder dengan ukuran diameter $5 \mathrm{~cm}$ dan tinggi $10 \mathrm{~cm}$ pada umur 28 hari. Perhitungan porositas dapat dilakukan dengan menggunkan rumus:

Porositas $=\frac{m b-m k}{V b} \times \frac{1}{\rho a i r} \times 100 \%$

Keterangan :

$$
\begin{array}{ll}
m_{b} & =\text { Berat basah benda uji } \\
m_{k} & =\text { Berat kering benda uji } \\
V_{b} & =\text { Volume benda uji } \\
P_{\text {air }} & =\text { Massa jenis air }
\end{array}
$$




\section{ANALISIS DAN PEMBAHASAN}

Hasil Pengujian Kuat Tekan

Tabel 1 Hasil Pengujian Kuat tekan Silinder 15 x $30 \mathrm{~cm}$

\begin{tabular}{|c|c|c|c|}
\hline $\begin{array}{l}\text { Umur } \\
\text { (Hari) }\end{array}$ & $\begin{array}{c}\text { KomposisiStrapping } \\
\text { Band } \\
(\%)\end{array}$ & $\begin{array}{c}\text { Ukuran } \\
\text { Strapping } \\
\text { Band } \\
(\mathrm{mm})\end{array}$ & $\begin{array}{c}\text { Kuat } \\
\text { Tekan } \\
\text { Rata-rata } \\
\text { (Mpa) }\end{array}$ \\
\hline \multirow{8}{*}{21} & \multirow{2}{*}{0} & 40 & 2,831 \\
\hline & & 50 & 2,831 \\
\hline & \multirow{2}{*}{3} & 40 & 3,491 \\
\hline & & 50 & 4,020 \\
\hline & \multirow{2}{*}{6} & 40 & 5,096 \\
\hline & & 50 & 7,360 \\
\hline & \multirow{2}{*}{9} & 40 & 5,190 \\
\hline & & 50 & 7,738 \\
\hline \multirow{8}{*}{28} & \multirow{2}{*}{0} & 40 & 3,114 \\
\hline & & 50 & 3,114 \\
\hline & \multirow{2}{*}{3} & 40 & 3,869 \\
\hline & & 50 & 4,114 \\
\hline & \multirow{2}{*}{6} & 40 & 4,246 \\
\hline & & 50 & 6,662 \\
\hline & \multirow{2}{*}{9} & 40 & 4,529 \\
\hline & & 50 & 7,455 \\
\hline
\end{tabular}

Sumber : Hasil Penelitian 
NAROTAMA JURNAL TEKNIK SIPIL

e-ISSN: 2460-3430

VOLUME 3 NOMOR 1 JUNI 2019

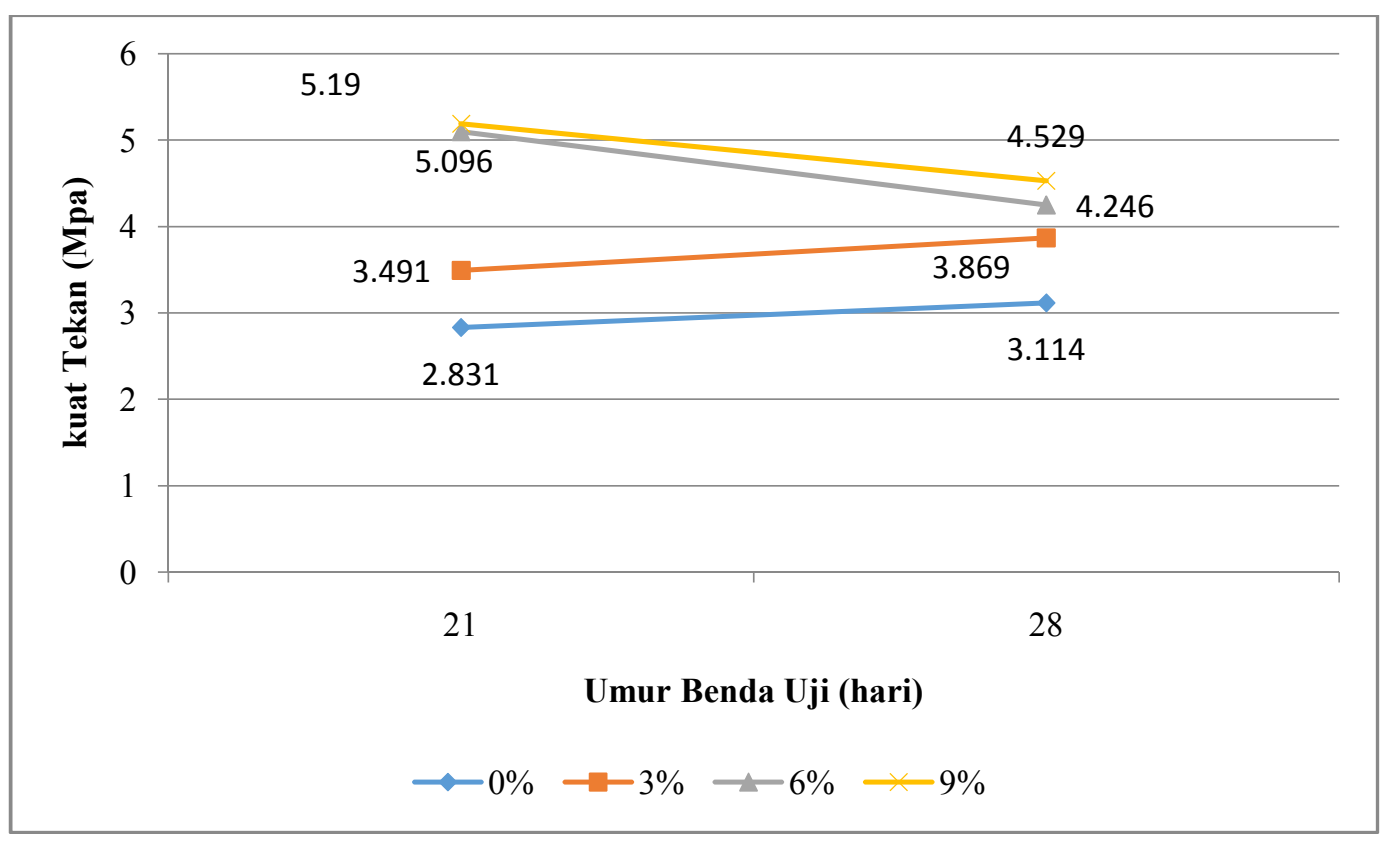

Gambar 2. Grafik Hubungan Komposisi Strapping Band Ukuran 40 mm dengan Kuat Tekan Bata Ringan Rata-rata

Dari tabel 1 dan Gambar 2 dapat dilihat bahwa kuat tekan bata meningkat dan menurun seiring dengan umur bata dan komposisi strapping band. Untuk bata ringan Komposisi 1 (normal) pada umur 21 hari mempunyai kuat tekan sebesar 2,831 Mpa dan mengalami peningkatan sebesar 0,28 Mpa (9,99\%) pada umur 28 hari yaitu 3,114 Mpa. Bata Komposisi 2 (FS 3\%) pada umur 21 hari mempunyai kuat tekan sebesar 3,491 Mpa dan mengalami peningkatan sebesar 0,38 Mpa ( 10,83\% ) pada umur 28 hari yaitu 3,869 Mpa. Bata komposisi 3 (FS 6\%) pada umur 21 hari mempunyai kuat tekan sebesar 5,096 Mpa dan mengalami penurunan sebesar $0,85 \mathrm{Mpa}(16,68 \%)$ pada umur 28 hari yaitu mencapai 4,246 Mpa. Bata komposisi 4 (FS 9\%) pada umur 21 hari mempunyai kuat tekan sebesar 5,19 Mpa dan mengalami penurunan sebesar 0,66 Mpa (12,74\%) pada umur 28 hari yaitu 4,529 Mpa. 
NAROTAMA JURNAL TEKNIK SIPIL

e-ISSN: 2460-3430

VOLUME 3 NOMOR 1 JUNI 2019

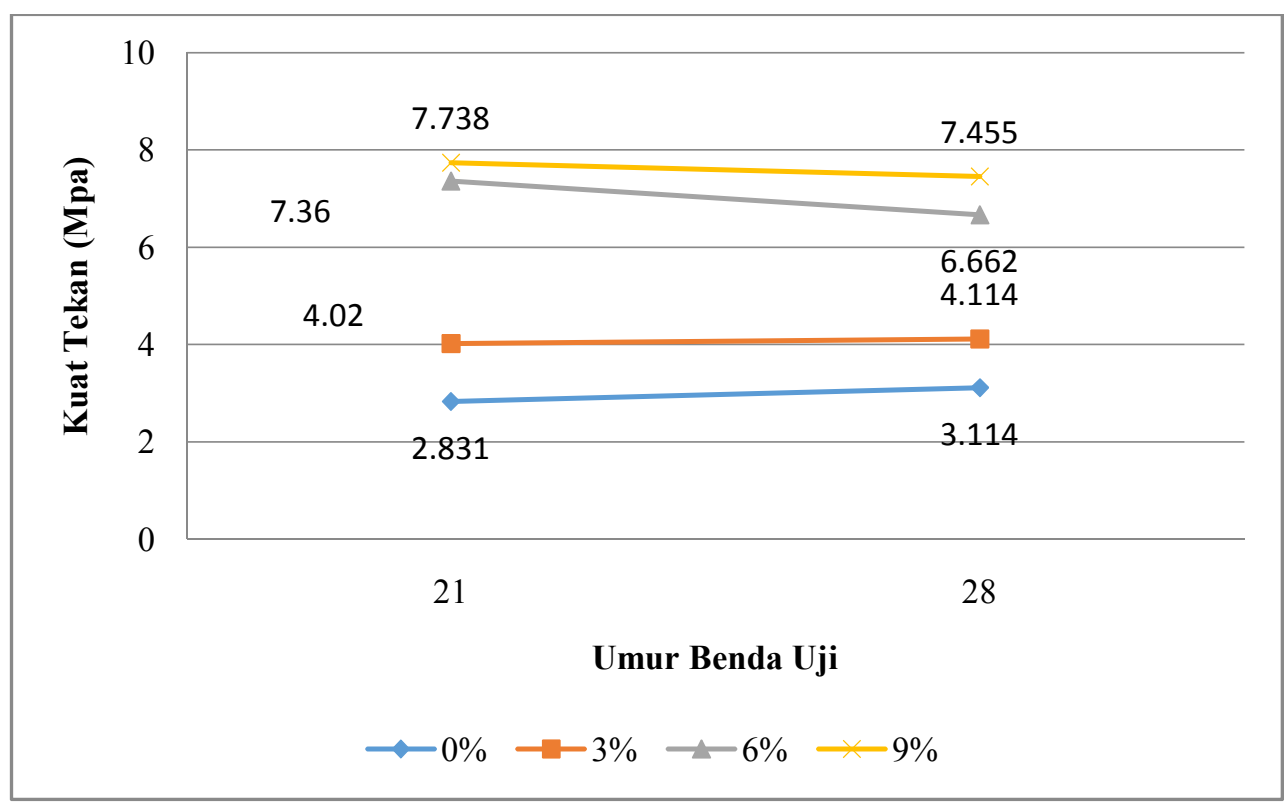

Gambar 3. Grafik Hubungan komposisistrapping Band Ukuran 50 mm dengan Kuat Tekan Bata Ringan Rata-rata

Dari Gambar 3 dapat dilihat bahwa kuat tekan bata meningkat dan menurun seiring dengan umur bata dan komposisi strapping band. Untuk bata ringan Komposisi 1 (normal) pada umur 21 hari mempunyai kuat tekan sebesar 2,831 Mpa dan mengalami peningkatan sebesar 0,28 Mpa (9,99\%) pada umur 28 hari yaitu 3,114 Mpa. Bata Komposisi 2 (FS 3\%) pada umur 21 hari mempunyai kuat tekan sebesar 4,020 Mpa dan mengalami peningkatan sebesar 0,094 ( 2,34\% ) pada umur 28 hari yaitu 4,114 Mpa. Bata komposisi 3 (FS 6\%) pada umur 21 hari mempunyai kuat tekan sebesar 7,360 Mpa dan mengalami penurunan sebesar 0,69 Mpa (9,48\%) pada umur 28 hari yaitu mencapai 6,662 Mpa. Bata komposisi 4 (FS 9\%) pada umur 21 hari mempunyai kuat tekan sebesar 7,738 Mpa dan mengalami penurunan sebesar 0,283 Mpa (3,66\%) pada umur 28 hari yaitu 7,455 Mpa. 


\section{NAROTAMA JURNAL TEKNIK SIPIL e-ISSN: $2460-3430$ \\ VOLUME 3 NOMOR 1 JUNI 2019}

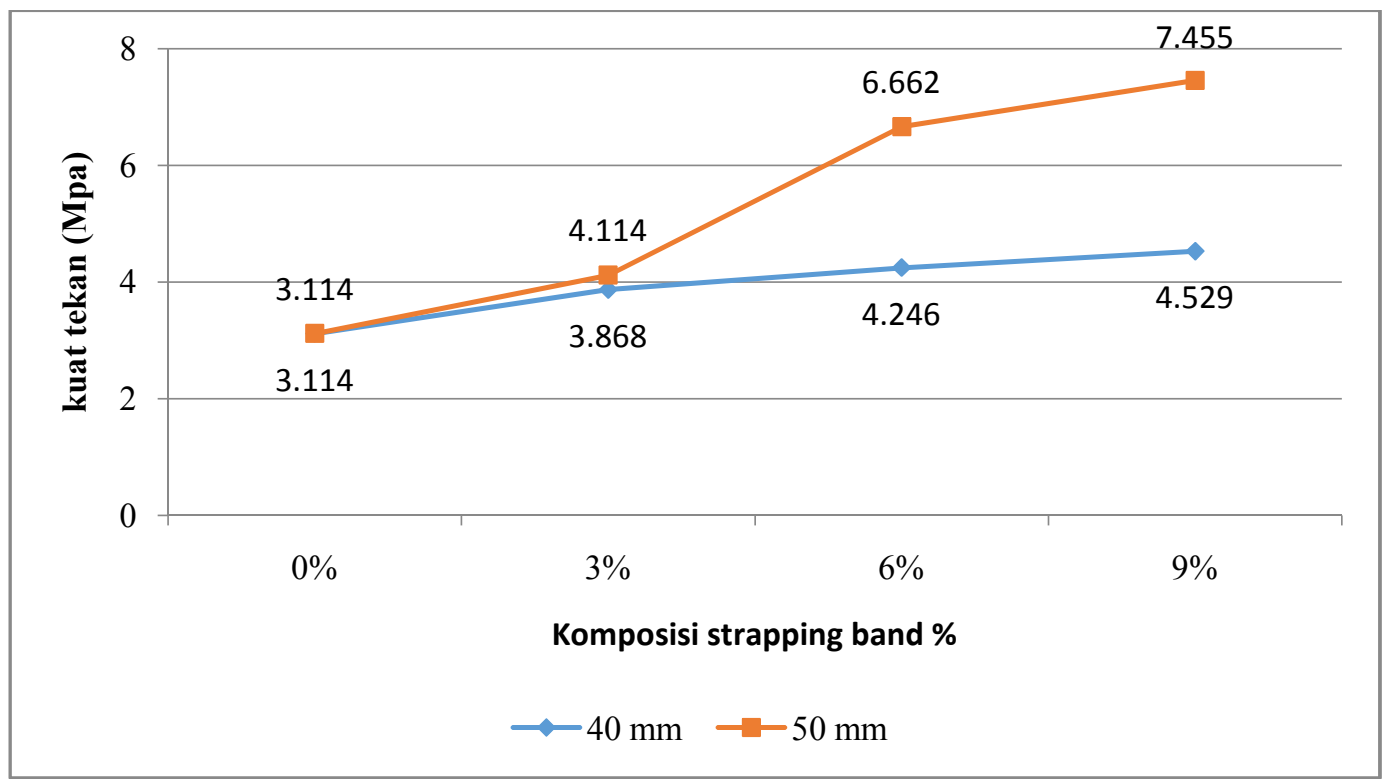

Gambar 4. Grafik Hubungan KomposisiStrapping Band Ukuran 40 mm dan 50 mm dengan Kuat Tekan Bata Ringan Rata-rata pada Umur 28 Hari.

Bedasarkan gambar 4 dapat dilihat bahwa kuat tekan bata meningkat seiring dengan umur bata dan komposisi strapping band. Untuk bata ringan Komposisi (normal) dengan ukuran strapping band $40 \mathrm{~mm}$ mempunyai kuat tekan sebesar 3,114 Mpa, komposisi (FS 3\%) dengan ukuran strapping band $40 \mathrm{~mm}$ mengalami peningkatan sebesar 0,76 Mpa (24,24\%) yaitu 3,869 Mpa, komposisi (FS 6\%) dengan ukuran strapping band $40 \mathrm{~mm}$ mengalami peningkatan sebesar 1,13 Mpa (36,35\%) yaitu 4,246 Mpa dan komposisi (FS 9\%) mengalami peningkatan sebesar 1,42 Mpa (45,44\%) yaitu 4,529 Mpa.

Komposisi (normal) dengan ukuran strapping band ukuran $50 \mathrm{~mm}$ mempunyai kuat tekan 3,114 Mpa, komposisi (FS 3\%) mengalami peningkatan sebesar 1 Mpa $(32,11 \%$ ) yaitu 4,114 Mpa, komposisi (FS 6\%) mengalami peningkatan sebesar 3,55 Mpa (114\%) yaitu 6,662 Mpa, komposisi (FS 9\%) mengalami peningkatan sebesar 4,34 (139,4\%) yaitu 7,455 Mpa. 
Tabel 2.Rekap Hasil Pengujian Kuat Tarik Belah Silinder 15 x $30 \mathrm{~cm}$ pada umur 28 hari

\begin{tabular}{|c|c|c|c|c|}
\hline $\begin{array}{c}\text { Komposisi } \\
\text { Strapping Band } \\
(\%)\end{array}$ & $\begin{array}{c}\text { Ukuran } \\
\text { Strapping } \\
\text { Band } \\
(\mathrm{mm})\end{array}$ & $\begin{array}{c}\text { Kuat Tarik } \\
\text { Belah } \\
\text { Rata-rata } \\
(\mathrm{Mpa})\end{array}$ & $\begin{array}{c}\text { Perubahan } \\
\text { kuat tarik } \\
\text { belah } \\
(\mathrm{Mpa})\end{array}$ & $\begin{array}{c}\text { Presentase } \\
\text { perubahan kuat } \\
\text { tarik belah } \\
(\%)\end{array}$ \\
\hline \multirow{2}{*}{$0 \%$} & 40 & 0,61 & 0 & $0,00 \%$ \\
\hline \multirow{2}{*}{$3 \%$} & 50 & 0,61 & 0 & $0,00 \%$ \\
\cline { 2 - 5 } & 50 & 0,68 & 0,07 & $10,29 \%$ \\
\hline \multirow{2}{*}{$6 \%$} & 40 & 0,87 & 0,26 & $29,88 \%$ \\
\hline \multirow{2}{*}{$9 \%$} & 50 & 0,90 & 0,29 & $32,22 \%$ \\
\hline & 50 & 0,92 & 0,31 & $33,69 \%$ \\
\hline
\end{tabular}

Sumber : Hasil Penelitian

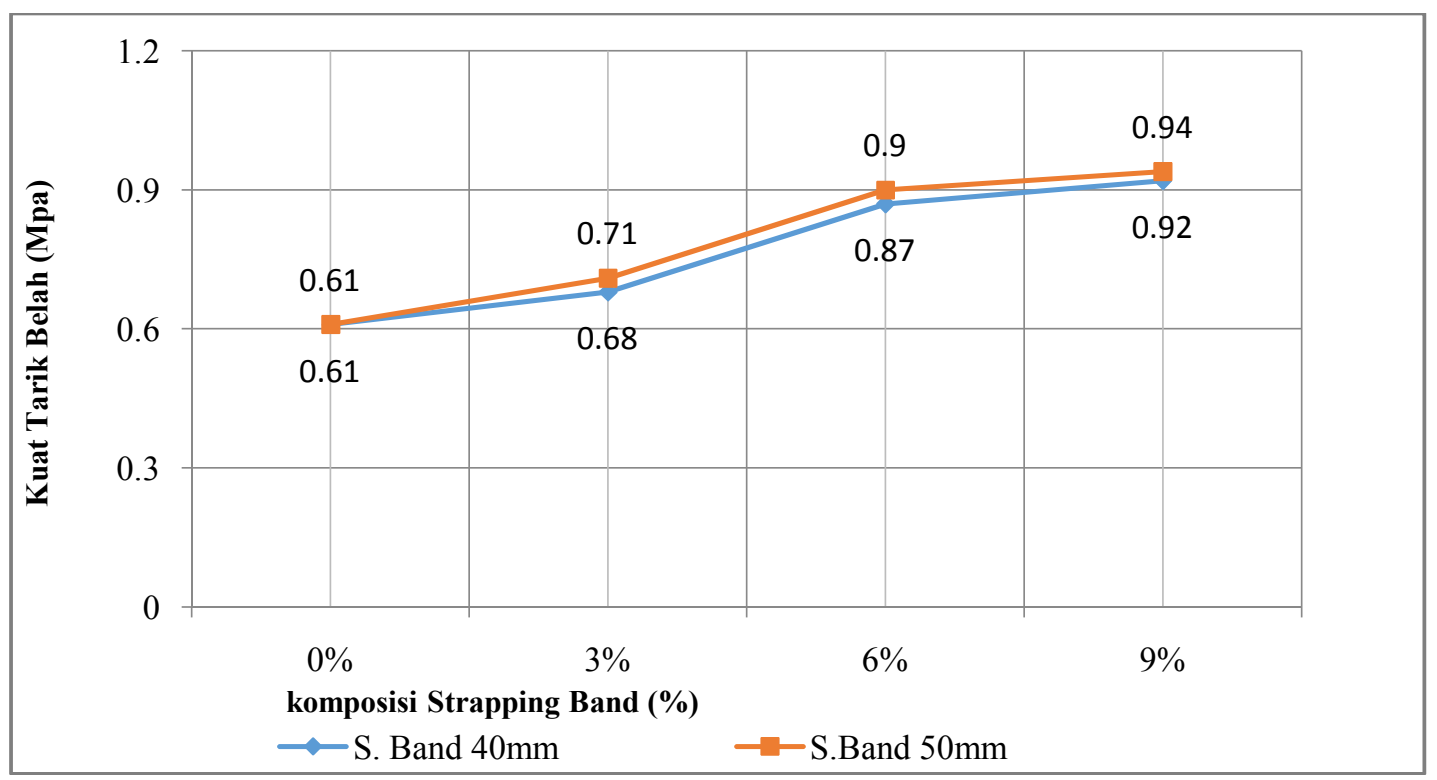

Gambar 5. Grafik Hubungan Komposisi Strapping Band dengan Kuat Tarik Belah Bata Ringan Rata-rata pada Umur 28 Hari. 


\section{NAROTAMA JURNAL TEKNIK SIPIL \\ e-ISSN: 2460-3430 \\ VOLUME 3 NOMOR 1 JUNI 2019}

Gambar 5. menunjukkan bahwa penambahan serat strapping band pada campuran bata ringan dapat menaikkan kuat tarik belah bata ringan. Dari data hasil pengujian menunjukan bahwa padabata ringan berumur 28 hari dengan komposisi strapping band $3 \%$ ukuran 40 mm mengalami peningkatan kuat tarik belah sebesar 0,07 Mpa $(11,47 \%)$ dan ukuran 50 mm peningkatan sebesar 0,1 Mpa (16,39\%), komposisi strapping band 6\% ukuran $40 \mathrm{~mm}$ mengalami peningkatan kuat tarik belah sebesar 0,26 Mpa (42,62\%) dan ukuran $50 \mathrm{~mm}$ peningkatan sebesar 0,29 Mpa (47,54\%) dan komposisi strapping band 9\% ukuran $40 \mathrm{~mm}$ mengalami peningkatan kuat tarik belah sebesar $0,31 \mathrm{Mpa}(50,82 \%)$ dan ukuran $50 \mathrm{~mm}$ peningkatan sebesar 0,33 Mpa (54,1\%).

Tabel 3. Hubungan Kuat Tekan dan Kuat Tarik Belah Bata Ringan Pada Umur 28 hari Strapping Band Ukuran $40 \mathrm{~mm}$ dan $50 \mathrm{~mm}$

\begin{tabular}{|c|c|c|c|c|}
\hline $\begin{array}{c}\text { Komposisi } \\
\text { Strapping Band } \\
(\%)\end{array}$ & $\begin{array}{c}\text { Ukuran } \\
\text { Strapping } \\
\text { Band } \\
(\mathbf{m m})\end{array}$ & $\begin{array}{c}\mathbf{f}^{\prime} \mathbf{c t} / \\
\text { Kuat Tarik } \\
\text { Belah (Mp) }\end{array}$ & $\begin{array}{c}\text { Kuat } \\
\text { Tekan } \\
\mathbf{( M p )}\end{array}$ & $\begin{array}{l}\text { Rasio antara kuat } \\
\text { tekan dan kuat } \\
\text { Tarik belah } \\
\boldsymbol{\alpha}=\mathbf{f}^{\prime} \mathbf{c t} / \sqrt{\mathbf{f}^{\prime} \mathbf{c}}\end{array}$ \\
\hline 0 & & 0,61 & 3,114 & 0,346 \\
\hline 3 & 40 & 0,68 & 3,869 & 0,354 \\
6 & & 0,87 & 4,246 & 0,422 \\
9 & & 0,92 & 4,529 & 0,432 \\
\hline 0 & & 0,61 & 3,114 & 0,346 \\
6 & 50 & 0,71 & 4,114 & 0,350 \\
\hline 9 & 0,90 & 6,662 & 0,349 \\
\hline
\end{tabular}

Sumber : Hasil Penelitian 


\section{NAROTAMA JURNAL TEKNIK SIPIL \\ e-ISSN: 2460-3430 \\ VOLUME 3 NOMOR 1 JUNI 2019}

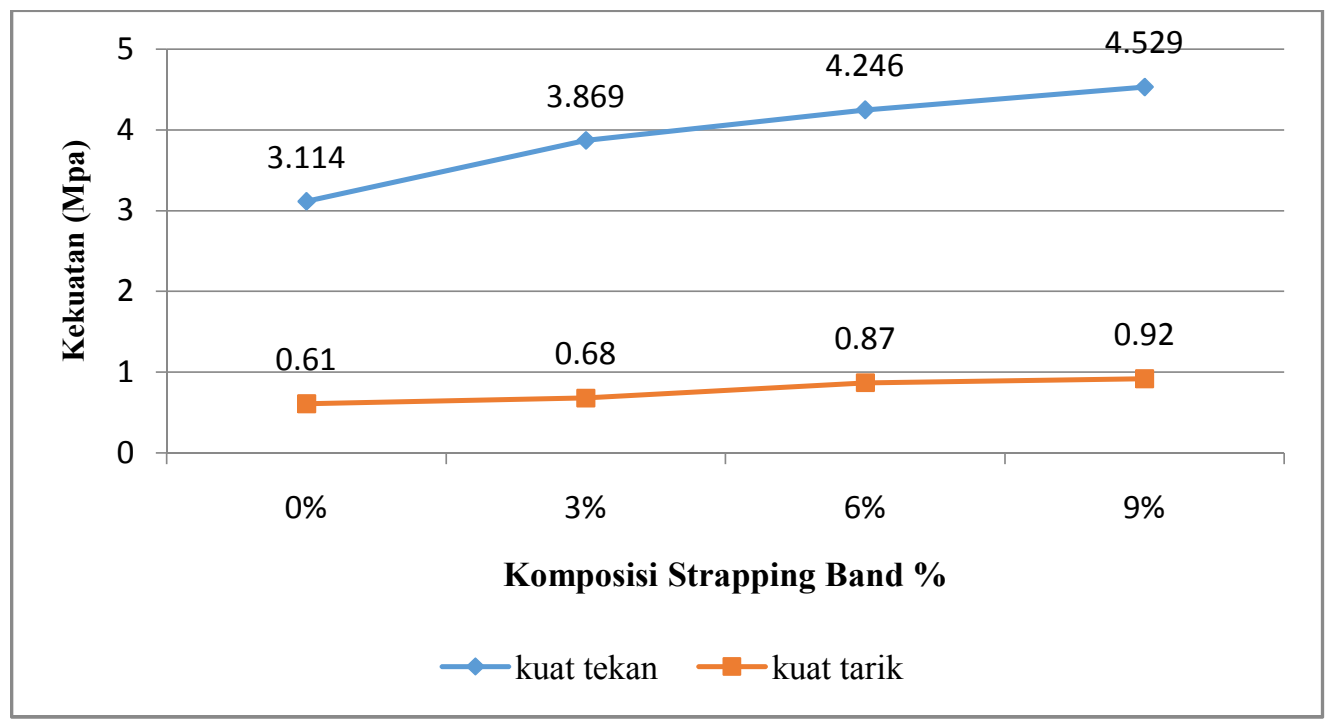

Gambar 6. Grafik Hubungan Kuat Tekan dan Kuat Tarik Belah Rata-Rata dengan Ukuran Strapping Band $40 \mathrm{~mm}$ pada Umur 28 Hari

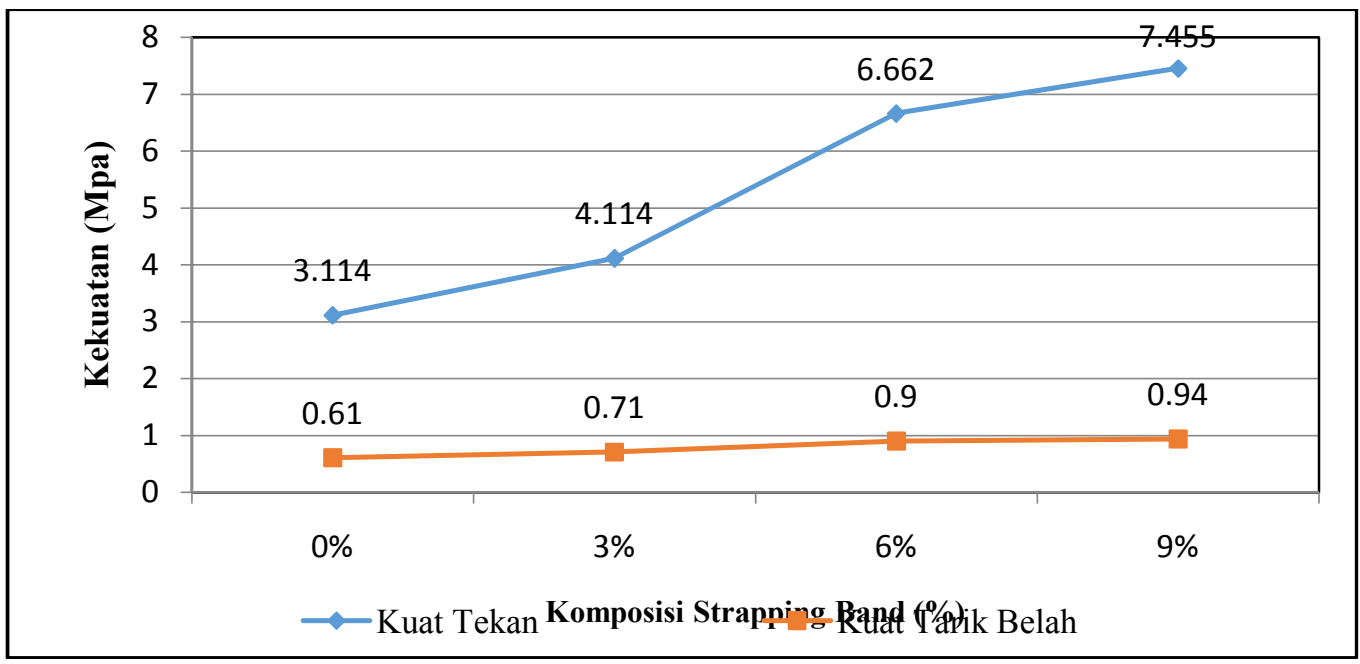

Gambar 7. Grafik Hubungan Kuat Tekan dan Kuat Tarik Belah Rata-Rata dengan Ukuran Strapping Band $50 \mathrm{~mm}$ pada Umur 28 Hari

Berdasarkan tabel 3, gambar 6 dan gambar 7 perbandingan antara kuat tekan dan tarik belah bata ringan dengan ukuran strappimg band $40 \mathrm{~cm}$ dan $50 \mathrm{~cm}$ menunjukan seiring bertambahnya penggunaan serat strapping band pada campuran bata ringan semakin meningkatkan kuat tekan maupun kuat tarik belah bata ringan. Dapat dilihat pada penambahan serat strapping band mengalami peningkatan kuat tekan dan kuat tarik belah secara signifikan pada setiap penambahan serat strapping band sampai kondisi maksimum pada komposisi strapping band $9 \%$. 


\section{Hasil Pengujian Berat Volume}

Tabel 4 Rekap Uji Berat Volume silinder 15 x $30 \mathrm{~cm}$ Pada Umur 28 Hari

\begin{tabular}{|c|c|c|}
\hline Komposisi & $\begin{array}{l}\text { Komposisi } \\
\text { Strapping } \\
\text { Band ( } \%)\end{array}$ & $\begin{array}{c}\text { Berat Volume } \\
\text { Rata-rata } \\
\left(\mathbf{k g} / \mathbf{m}^{\mathbf{3}}\right)\end{array}$ \\
\hline \multirow{4}{*}{$40 \mathrm{~mm}$} & 0 & 1455 \\
\hline & 3 & 1443 \\
\hline & 6 & 1433 \\
\hline & 9 & 1430 \\
\hline \multirow{4}{*}{$50 \mathrm{~mm}$} & 0 & 1455 \\
\hline & 3 & 1442 \\
\hline & 6 & 1435 \\
\hline & 9 & 1421 \\
\hline
\end{tabular}

Sumber : Hasil Penelitian

Dari Tabel 4 dapat disimpulkan bahwa semakin besar penambahan fiber strappingband pada campuran bata ringan, maka berat volume bata ringan akan semakin ringan. Berat volume bata ringan normal tanpa menggunakan fiber strappingband $0 \%$ lebih berat dibanding bata ringan dengan menggunakan fiber strappingband. Pada komposisi 3\% dan $6 \%$ penggunaan fiber strapping band justru semakin meringankan berat volume bata ringan, fiber strapping band stabil pada komposisi campuran fiber strapping band $9 \%$ terjadi penurunan berat volume yang signifikan. Berarti penggunaan fiber strappingband cocok pada komposisi 3\%, 6\% dan 9\% sehingga berat volumenya lebih kecil dari 1600 $\mathrm{kg} / \mathrm{m}^{2}$ (Ngabdurrochman, 2009). 
VOLUME 3 NOMOR 1 JUNI 2019

\section{Hasil Pengujian Porositas}

Tabel 5. Hubungan Komposisi Strapping Band dengan Porositas

\begin{tabular}{|c|cc|}
\hline $\begin{array}{c}\text { Ukuran } \\
\text { S. Band } \\
(\mathbf{m m})\end{array}$ & $\begin{array}{c}\text { Komposisi } \\
\text { Strapping } \\
\text { Band } \\
\mathbf{( \% )}\end{array}$ & $\begin{array}{c}\text { Porositas } \\
\text { Rata- } \\
\text { Rata } \\
\mathbf{( \% )}\end{array}$ \\
\hline 40 & 0 & 0,11 \\
& 3 & 0,15 \\
& 6 & 0,17 \\
& 9 & 0,20 \\
& 0 & 0,11 \\
& 3 & 0,19 \\
& 6 & 0.21 \\
\hline & 9 & 0,23 \\
\hline
\end{tabular}

Sumber : Hasil Penelitian

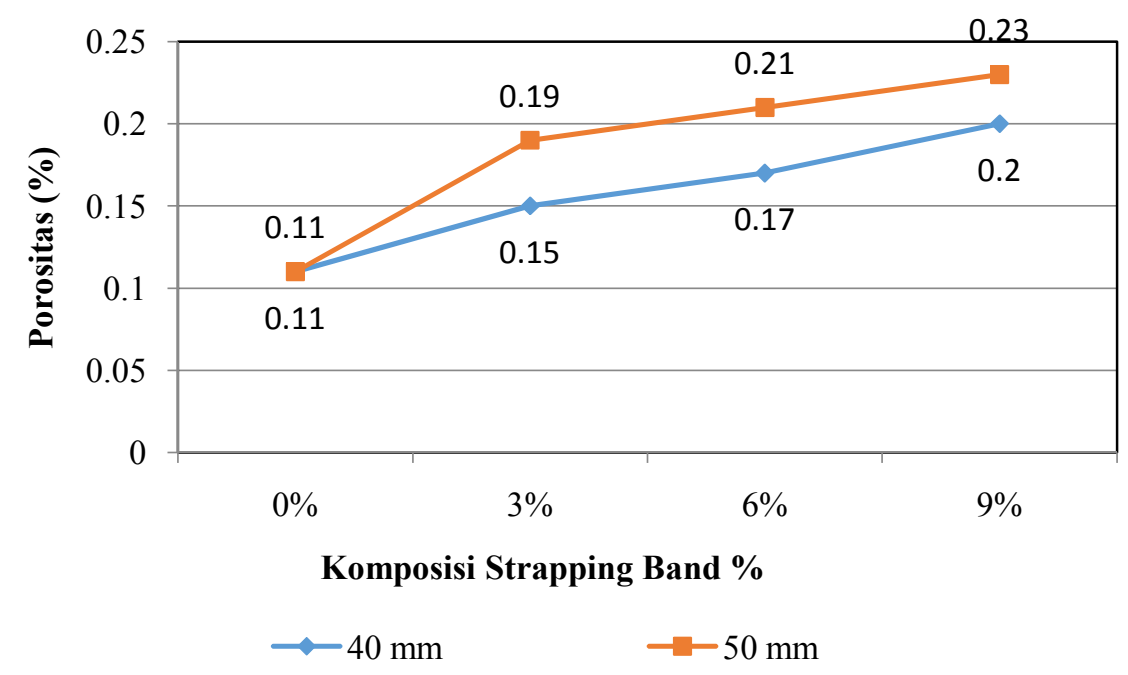

Gambar 7.Grafik Hubungan Komposisi Strapping Band dengan Porositas Bata Ringan 


\section{NAROTAMA JURNAL TEKNIK SIPIL e-ISSN: $2460-3430$ VOLUME 3 NOMOR 1 JUNI 2019}

Dari grafik 7 untuk ukuran strapping band $40 \mathrm{~mm}$ dapat dilihat pada penambahan strapping band $3 \%$ meningkatkan porositas menjadi $0,15 \%$, penambahan strapping band $6 \%$ meningkatkan porositas menjadi $0,17 \%$, penambahan strapping band $9 \%$ meningkatkan porositas menjadi $0,20 \%$, begitu juga untuk ukuran strapping band $50 \mathrm{~mm}$ dapat dilihat pada penambahan strapping band 3\% meningkatkan porositas menjadi $0,19 \%$, penambahan strapping band $6 \%$ meningkatkan porositas menjadi $0,21 \%$, penambahan strapping band $9 \%$ meningkatkan porositas menjadi $0,23 \%$.

\section{KESIMPULAN}

Berdasarkan hasil penelitian dapat disimpulkan:

Pengaruh kuat tekan dan kuat tarik belah bata ringan pada penambahan fiber strapping band dengan komposisi $0 \%, 3 \%, 6 \%$ dan 9\% terhadap umur benda uji mengalami peningkatan secara signifikan dan berat volume bata lebih ringan.

Komposisi strapping band optimum terjadi komposisi $9 \%$ dengan panjang fiber strapping band $50 \mathrm{~mm}$ dengan nilai kuat tekan sebesar 7,455 Mpa, sedangkan kuat tarik sebesar 0,94 Mpa dan berat volume $1421 \mathrm{~kg} / \mathrm{m} 3$.

\section{DAFTAR PUSTAKA}

1. A. Short \& W. Kinniburgh. "Lightweight Concrete". (1978). Book, Applied Science Publishers, london.

2. Amalia Novita Pratiwi 2017., "Pengaruh Penambahan Serat Polypropylene Terhadap Sifat Mekanis Beton Normal Dengan Penggunaan Copper Slag Sebagai Substitusi Agregat Halus". Jurnal Rekayasa Teknik Sipil, Vol 3, No 3/REKAT/17 (2017)

3. Amir Murtono (2015)., "Pemanfaatan Foam Agent dan Material Lokal Dalam Pembuatan Bata Ringan”. Diploma Thesis, (http://eprints.ums.ac.id./id/eprint/37581), Universitas Muhammadiyah Surakarta.

4. Andriati Amir Husin, Rudi Setiadji Agustiningtyas (2008)., "Pengaruh Penambahan Foam Agent Terhadap Kualitas Bata Beton”. Jurrnal Permukiman, Vol 3, No 3 (2008)

5. ASTM C 20 - 2000., "Metode Uji Standar Untuk Porositas" ASTM International, West Conshohocken,

6. Dharma Giri, I.B, dkk, 2008., "Kuat Tekan Modulus Elastisitas Beton Dengan Penambahan Styrofoam (Styrocon)”, Jurnal Ilmiah Teknik Sipil Vol.12, No.1, Januari 2008, diakses tanggal 7 September 2010.

7. Hibbab Tiro (2015)., "Permanfaatan Penambahan Polyester Strapping Band Untuk Mortar Fiber Ditinjau Terhadap Kuat Tarik Belah dan Kuat Tekan”. Skripsi, Universitas Dr. Soetomo 


\section{NAROTAMA JURNAL TEKNIK SIPIL e-ISSN: $2460-3430$ VOLUME 3 NOMOR 1 JUNI 2019}

8. Kantius Wenda (2018)., "Pengaruh Komposisi Komposisi Campuran Mortar Terhadap Kuat Tekan”. Jurnal Perencanaan dan Rekayasa Sipil, vol. 1, Nomor 1, Maret 2018, Teknik Sipil, Fakultas Teknik Universitas Dr. Soetomo.

9. Khairizal Yuri (2015)., "Pengaruh Penambahan Serat Polypropylene Terhadap Sifat Mekanis Beton Normal". Jurnal online mahasiswa, Vol. 2, Nomor 2, Teknik Sipil, Fakultas Teknik, Universitas Riau, October 2015

10. Malau, F. Blasius (2014)., "Penelitian Kuat Tekan dan Berat Jenis Mortar Untuk Dinding Panel dengan Membandingkan dengan Penggunaan Pasir Bangka dan Pasir Baturaja dengan Tambahan Foaming Agent dan Silica Fume”. Jurnal Teknik Sipil dan Lingkungan Vol. 2, No. 2, Juni 2014, ISSN 2355-374X, Universitas Sriwijaya, Palembang.

11. Mikhael Frederikus Kung (2015)., "Pengaruh komposisi Serat Polypropylene Terhadap Sifat Mekanik Beton" Laporan Tugas Akhir, Universitas Atma Jaya Yogyakarta, September 2015.

12. Muhammad Syaiful Yahya (2015)., "Pengaruh Penambahan Serat Polyester Pada Beton Ringan Dengan TeknologiGas Terhadap Kuat Tekan, Kuat Tarik Belah dan Modulus Elastisitas" Thesis, (http://eprints.uns.ac.id/id/eprint/18966), Universitas Sebelas Maret, Surakarta.

13. Ngabdurrochman, (2009). （ http://gie713.blogspot.com/2009/10 makalahteknologibetonngabdurrochman.html) Diakses 5 Januari 2010.

14. Raka Mahendra Firdaus ( 2018)., "Pembuatan Bata Ringan Dengan Styrofoam dan Semen Putih". Tugas Akhir, Universitas Dr. Soetomo.

15. SNI T-03-3449-2002., "Tata Cara Rencana Pembuatan Campuran Beton Ringan Dengan Agregat Ringan" . Badan Standarisasi Nasional, Bandung.

16. Susanto, Muhammad Reza Arief (2016).," Pengaruh Penambahan Foam Agent Pada Pembuatan Beton Busa (Tinjauan Terhadap Densitas, Kuat Tekan dan Water Absorption)". Thesis,(http://eprints.umm.ac.id/id/eprint/33471), Universitas Muhammadiyah Malang.

17. SNI 03 - 2491 - 2002., "Metode Pengujian Kuat Tarik Belah Beton”. Badan Standarisasi Nasional, Bandung.

18. SNI (1974-2011)., "Cara UjiKuatTekanBetonDengan Benda UjiSilinder”. Badan Standarisasi Nasional, Bandung.

19. Tjokrodimuljo, Kardiyono (2007)., Teknologi Beton. Buku, Biro Penerbit Jurusan Teknik Sipil, Fakultas Teknik Universitas Gajah Mada, Yogyakarta. 
20. Wahyu kartini (2007) “Penggunaan Serat Polypropylene Untuk Meningkatkan Kuat Tarik Belah Beton” Jurnal rekayasa perencanaan, Vol. 4, No.1, Oktober 2007 